\title{
The sympathetic role as an antagonist of erection
}

\author{
W. Diederichs, C. G. Stief, F. Benard, R. Bosch, T. F. Lue, and E. A. Tanagho \\ Department of Urology, University of California, School of Medicine, San Francisco, CA, USA
}

Accepted: May 1, 1990

Summary. The effects of the lumbar and pelvic sympathetic system on penile erection were studied in a canine model. Erection was induced by cavernous nerve stimulation and detumescence by sympathetic trunk stimulation. Erection induced by cavernous nerve stimulation normally subsides slowly. After discontinuation of electrical stimulation the intracavernous pressure drops within a mean of $291 \mathrm{~s}$ to $50 \%$ and after a mean of $372 \mathrm{~s}$ to $10 \%$ of the highest level. However, stimulation of the sympathetic trunk at the level of L4-S1 applied directly after discontinuation of cavernous nerve stimulation accelerated this drop of intracavernous pressure significantly: to $50 \%$ after a mean of $19 \mathrm{~s}$ and to $10 \%$ after a mean of $36 \mathrm{~s}$. If stimulation of the sympathetic trunk was initiated $20 \mathrm{~s}$ before cavernous nerve stimulation, the pressure rise was aborted completely. Neurostimulation of the hypogastric nerves alone or in combination with cavernous nerve stimulation did not change the intracavernous pressure. These results were not altered after neurotomy of the pudendal or hypogastric nerves. The main pathway of the fibers from the sympathetic trunk to the penis seems to run via the pelvic plexus. The stimulation voltage and frequency to induce erection or detumescence were equivalent. Our results suggest that an elevated central sympathetic tone may be one of the causes of psychogenic impotence.

Key words: Sympathetic trunks - Erection - Detumescence - Impotence

The erectile tissue of the corpora cavernosa is under the control of the parasympathetic and sympathetic nervous systems [11]. As shown in previous horseradish peroxidase studies in dogs [9], the cavernous nerve fibers are connected to central ganglion cells in the spinal cord at the level of T12-L3 (sympathetic centers) and S1-S3 (parasympathetic centers). Early electrophysiological research [8] demonstrated synergic and antagonist effects on erection during hypogastric nerve stimulation. Semans and Langworthy [14] reported abolition of erection by abdominal sympathetic trunk stimulation in cats. Bilateral pudendal and hypogastric neurotomies did not block this phenomenon. However, stimulation of the peripheral stumps of the hypogastric nerves led to a quicker decrease of erection induced by nervi erigentes stimulation. Sjöstrand and Klinge [15] reported a vasoconstrictor pathway to the penis by stimulation of the sacrococcygeal part of the sympathetic trunk and a vasodilatator pathway by stimulation of the hypogastric nerves in rabbits.

Previous reports on the effects of sympathetic nerve stimulation on penile erection are contradictory $[1,4,14$, 15]. This study was undertaken to clarify intracavernous pressures changes during erection and detumescence induced by neurostimulation of the sympathetic and parasympathetic system.

\begin{abstract}
Materials and methods
Animal preparations

The experiments were carried out on fourteen mongrel dogs (18$29 \mathrm{~kg}$ ). The dogs were premedicated with acepromazine $0.1 \mathrm{mg} / \mathrm{kg}$ and ketamine $5 \mathrm{mg} / \mathrm{kg}$ intramuscularly and anesthesized by intravenous administration of pentobarbital (100-130 mg as a bolus; maintenance with additional $10 \mathrm{mg}$ dosages as required). All animals were breathing spontaneously. Intravenous saline perfusion was given $2 \mathrm{ml} \cdot \mathrm{kg}^{-1} \cdot \mathrm{h}^{-1}$. After all preparations and surgical exposures the dogs were anticoagulated with sodium heparin $(1,000 \mathrm{U}$ as a bolus; maintenance $100 \mathrm{U} / \mathrm{h}$ ) to prevent blood clots inn the recording lines.
\end{abstract}

\section{Surgical procedures}

The dogs were placed in the supine position. The abdomen was entered via a midline incision. The midshaft of the penis was dissected free from skin and subcutaneous tissue. After dissection of the perivesical fat, bipolar cuff electrodes (Avery Lab) were placed around both cavernous nerves. The same electrodes were also applied to the main hypogastric trunk as well as to the distal parts of the left and right hypogastric nerves. After exposure of the sympathetic trunks lateral to the aorta, electrodes were implanted 

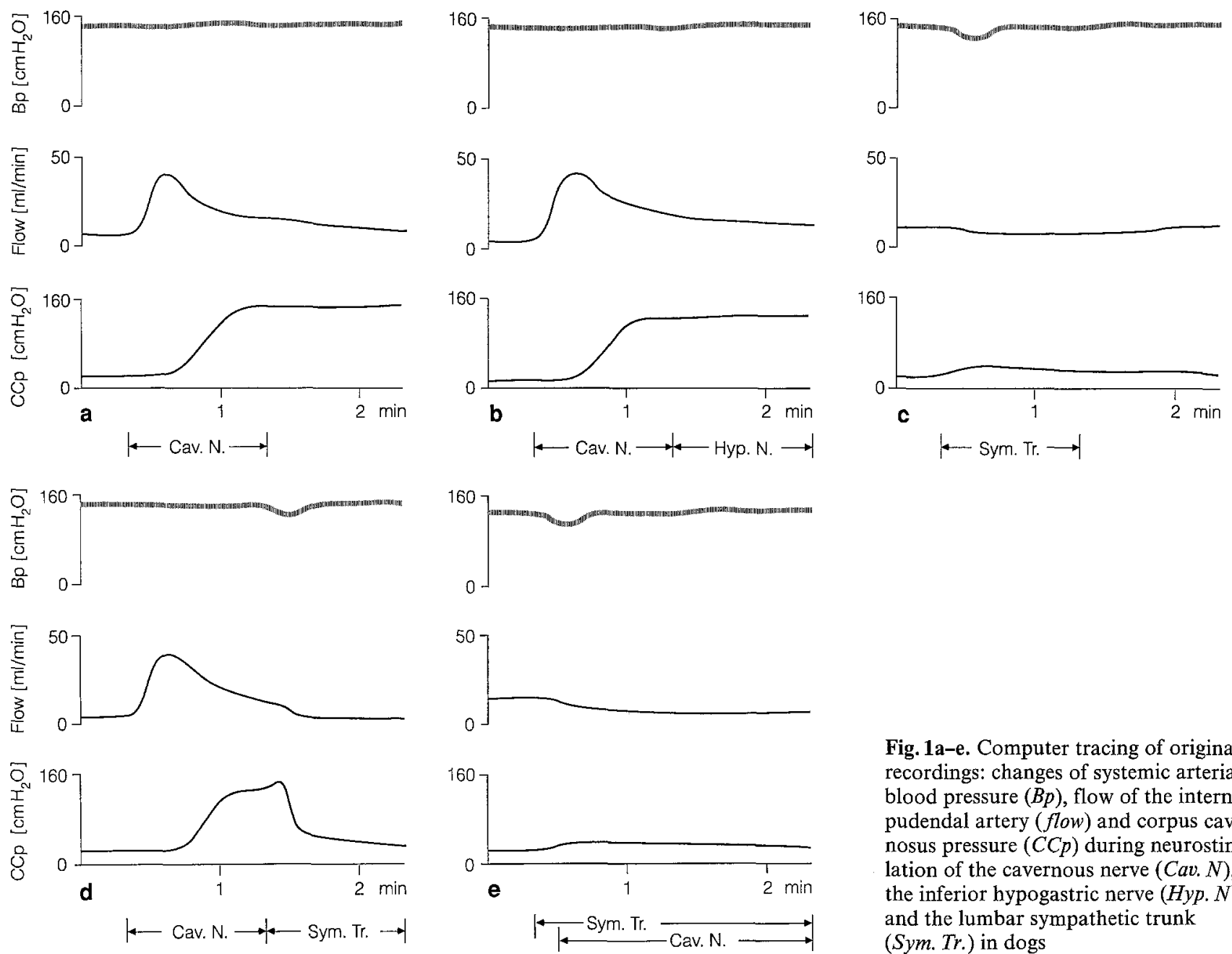

Fig. 1a-e. Computer tracing of original recordings: changes of systemic arterial blood pressure $(B p)$, flow of the internal pudendal artery (flow) and corpus cavernosus pressure $(C C p)$ during neurostimulation of the cavernous nerve ( $\mathrm{Cav} . N)$, the inferior hypogastric nerve $(H y p . N)$, and the lumbar sympathetic trunk $(S y m . T r$.$) in dogs$

at different levels (L4-S1). The electrodes were connected to separate receivers (Avery Lab) which were activated by an external transmitter (Avery Lab) via antennae. Stimulation parameters were $1.2-6 \mathrm{~V}$ and $20 \mathrm{~Hz}$. At the end of the studies different nerves were cut in six dogs: (1) the hypogastric trunk just above the bifurcation, (2) the hypogastric nerve $3 \mathrm{~cm}$ distal to its bifurcation, (3) the pudendal nerve $1 \mathrm{~cm}$ distal from its junction with the pelvic branches, (4) the sympathetic trunks at L4, L5, and L7. Cuff electrodes were placed around the nerve endings.

\section{Recording}

Both corpora cavernosa were punctured with a 21 gauge scalp vein needle. The right femoral artery and in two cases the distal aorta were cannulated with a 18 gauge angiocath needle. All of these were connected to Statham transducers. In eleven dogs a flow probe (1.5 mm, Transonic system) was placed around the internal pudendal artery. A Grass Polygraph Model 7 was used for recording.

\section{Results}

\section{Baseline data}

In the flaccid state the intracavernous pressure ranged from $5-15 \mathrm{cmH}_{2} \mathrm{O}$. A flow of $4-15 \mathrm{ml} / \mathrm{min}$ was recorded from the internal pudendal artery.

\section{Cavernous nerve stimulation}

A voltage of $1.2-6 \mathrm{~V}$ (medium $2.2 \mathrm{~V}$ ) was used to induce an erection with an intracavernous pressure at $85 \%-100 \%$ of the systemic blood pressure. Higher voltages $(>6 \mathrm{~V})$ could not induce a higher intracavernous pressure. Within 10$20 \mathrm{~s}$ after the start of stimulation an initial peak flow of $26-$ $40 \mathrm{ml} / \mathrm{min}$ was recorded from the internal pudendal artery. After an additional $40-50 \mathrm{~s}$ of stimulation an intracavernous pressure plateau of $120-180 \mathrm{cmH}_{2} \mathrm{O}$ was reached (Fig. 1a). In the meantime, the arterial flow dropped to $12-20 \mathrm{ml} / \mathrm{min}$ (maintenance flow). The neurostimulation was stopped after $1 \mathrm{~min}$. The intracavernous pressure decreased slowly to $50 \%$ of the highest level after a mean time interval of $291 \mathrm{~s}$ and dropped to $10 \%$ after $372 \mathrm{~s}$. The arterial maintenance flow $(12-20 \mathrm{ml} / \mathrm{min})$ decreased to the baseline flow $(4-15 \mathrm{ml} / \mathrm{min})$ within 10 $30 \mathrm{~s}$ after neurostimulation was terminated.

\section{Sympathetic nerve stimulation}

Neurostimulation of the hypogastric nerves alone or in combination ( $20 \mathrm{~s}$ before, directly after) with cavernous nerve stimulation did not change the intracavernous pressure (Fig. 1b), the arterial flow, or the systemic blood 
pressure. Stimulation (1.2-6 V) of the sympathetic trunk ( $\mathrm{L} 4$ up to $\mathrm{S} 1$ ) alone induced a transiently small rise of 8-10 $\mathrm{cmH}_{2} \mathrm{O}$ in intracavernous pressure (Fig. 1c). After 10-20 s a drop of 5-30 $\mathrm{cmH}_{2} \mathrm{O}(5-15 \mathrm{~s})$ in the mean arterial blood pressure was noted. When the sympathetic trunk (L4-S1) was stimulated $(1.2-6 \mathrm{~V}$, mean $2.6 \mathrm{~V})$ after full erection was induced by cavernous nerve stimulation, the intracavernous pressure increased immediately (Fig. 1d) by an additional 5-10 $\mathrm{cmH}_{2} \mathrm{O}$ but gradually decreased after 5$10 \mathrm{~s}$ to $50 \%$ within a mean time of $19 \mathrm{~s}$ and to $10 \%$ after a mean time of $36 \mathrm{~s}$. The arterial flow in the pudendal artery decreased to the baseline flow within 20-32 s. When the sympathetic trunk was stimulated $10-20$ s before stimulation of the cavernous nerve, the cavernous pressure rise was aborted completely (Fig. 1e). A flow increase in the pudendal artery could not be obtained; usually a slight flow decrease of $2-6 \mathrm{ml} / \mathrm{min}$ occurred.

In these experiments an increase of the stimulation voltage above $6 \mathrm{~V}$ did not result in a better response.

There are many variations in the anatomy of the lumbosacral sympathetic trunks especially, of interconnections and fusions of the trunks $[12,16]$.

Therefore all neurostimulation studies of the sympathetic trunks were undertaken bilaterally.

\section{Neurostimulation after different neurotomies}

Sectioning the hypogastric nerve (main trunk, distal right and left branches) did not alter the cavernous and sympathetic trunk stimulation results. Neither did uniand bilateral neurotomies of the pudendal nerves or lumbar sympathetic trunk.

\section{Discussion}

We found that sympathetic trunk stimulation can induce detumescence or can abolish cavernous nerve-induced erection. All these results were not altered after neurotomy of the pudendal or hypogastric nerves.

Previous studies have shown that erection can be induced by unilateral cavernous nerve stimulation [10]. The basic mechanism of arterial flow increase followed by penile tumescence was first described by Eckhard [2] and reaffirmed by Francois-Frank [3]. The quick increase of intracorporeal pressure was always followed after termination of cavernous nerve stimulation by a slow detumescence (mean 372s). Kölliker [6] proposed that smooth muscle relaxation of the arteries supplying the cavernous bodies and in their walls is essential to penile erection. Contraction of the smooth muscle is followed by detumescence of the penis. In addition, rhythmic contractions of animal and human smooth muscle stripes in an organ bath [5] were observed as part of an autoregulation mechnism. We consider that the slow detumescence seems to be under control of a local peripheral mechanism. After the sympathetic trunk in rabbits was sectioned the penis first protruded but then relaxed after 1-2h [15]. In our experiments the intracavernous pressure was stable after sectioning of the sympathetic trunk up to the end of the experiments (about $3 \mathrm{~h}$ ). Our data suggested that faster detumescence or its suppression by sympathetic trunk stimulatin is due to the effects on penile smooth muscles which regulate arterial flow and cavernous pressure. The neutral pathway via the sympathetic trunks seems to be the main mediator of detumescence.

In contrast to studies by Semans and Langworthy [14] and others [4], our investigations showed no effect of hypogastric neurostimulation on intracavernous pressure using similar voltages (up to $6 \mathrm{~V}, 20 \mathrm{~Hz}$ ). However, neurostimulation of the hypogastric nerve using $14 \mathrm{~V}$ induced detumescence [4]. We suggest that under these conditions an additional activation of the sympathetic trunk cannot be excluded. All these findings seem to be relevant only in acute experiences. In a chronic animal study after abdominal sympathectomy in male cats Roots and Bard [13] no alteration of sexual behavior.

Our neurotomy experiment proved that the effect from stimulation of the lumbal sympathetic trunks is not due to an inhibition of central ganglia. The main pathway of these sympathetic fibers seems to run via the pelvic plexus to the penis. Sjöstrand and Klinge [15] showed in rabbits that the penis is innervated by the sacrococcygeal sympathetic trunk. In cats Kuo et al. [7] found that the number of sympathetic neurons projecting to the pelvic nerve was about $75 \%$ of the number projecting to the pudendal nerves. Their electrophysiological data confirmed the presence of a sympathetic pathway from the sympathetic trunk to the pelvic nerve. Concerning our data we suggest that the large number of sympathetic fibers inside the pudendal nerve seems to have no effect on detumescence. These findings are contrary to the observations of Semans and Langworthy [14], who did not describe their stimulation parameters. On the other hand, the temporary drop in systemic blood pressure (aorta and femoral artery) may be due to a strong vasodilator effect mediated by some of these sympathetic fibers.

Our results suggest that an elevated central sympathetic tone may be one of the causes of psychogenic impotence and may shed some light on its management.

We conclude that:

1. Detumescence seems to be mediated by peripheral (slow detumescence) and central regulation (fast detumescence).

2. The neutral pathway runs from the sympathetic trunk via the pelvic plexus to the penis. These sympathetic fibers control smooth muscles in the penile arteries and the erectile tissue of the cavernous bodies.

3. The effective parameters of cavernous and sympathetic nerves are equivalent. Stimulation of the hypogastric nerve with the same voltage needed for cavernous nerve or sympathetic trunk stimulation has no effect on penile erection.

\section{References}

1. Carati CJ, Creed KE, Keogh EJ (1987) Autonomic control of penile erection in the dog. J Physiol 384:525

2. Eckhard C (1863) Untersuchungen über die Erektion des Penis beim Hund. Beitr Anat Phys 3:123 
3. Francois-Frank M (1895) Recherches sur l'innervation vasomotrice du pénis ( $1^{\text {er }}$ mémoire). Techniques des explorations et principaux résultants. Arch Phys Pathol 27:122

4. Jünemann KP, Persson-Jünemann C, Lue TF, Tanagho EA (1989) Neurophysiological aspects of penile erection: the role of the sympathetic nervous system. Br J Urol 64:84

5. Klinge E, Sjöstrand NO (1977) Comparative study of some isolated mammalian smooth muscle effectors of penile erection. Acta Physiol Scand 100:354

6. Kölliker A (1852) Das anatomische und physiologische Verhalten der cavernösen Körper der Sexualorgane. Verh Phys Med Ges 2:118

7. Kuo DC, Hisamitsu T, de Groat WC (1984) A sympathetic projection from sacral paravertebral ganglia to the pelvic nerve and to postganglionic nerves on the surface of the urinary bladder and large intestine of the cat. J Comp Neurol 226:76

8. Langley JN, Anderson HK (1895) The innervation of the pelvic and adjoining viscera. J Physiol 19:71

9. Lue TF, Zeineh SJ, Schmidt RA, Tanagho EA (1984) Neuroanatomy of penile erection: its relevance to iatrogen impotence. $\mathbf{J}$ Urol 131:273

10. Lue TF, Schmidt RA, Tanagho EA (1985) Electrostimulation and penile erection. Urol Int 40:60

11. McConnel J, Benson GS, Wood J (1984) Autonomic innervation of the mammalian penis: a histological and physiologica study. $\mathbf{J}$ Neural Transm 45:27
11. McConnel J, Benson GS, Wood J (1984) Autonomic innervation of the mammalian penis: a histological and physiologica study. $\mathrm{J}$ Neural Transm 45:227

12. Mehler WR, Fischer JC, Alexander WF (1952) The anatomy and variations of the lumbosacral sympathetic trunk in the dog. Anat Rec 113:421

13. Root WS, Bard P (1947) The mediation of feline erection through sympathetic pathways with some remarks on sexual behavior after deofferentation of the genitalia. Am J Physiol 151:80

14. Semans JH, Langworthy OR (1938) Observation on the neurophysiology of sexual function in the male cat. J Urol 40:836

15. Sjöstrand NO, Klinge E (1979) Principal mechanisms controlling penile retraction and protrusion in rabbits. Avta Physiol Scand 106:199

16. Wozniak W (1966) Sacral segments of the sympathetic trunks (dog, cat, man). Folia Morphol (Warsz) 25:396

Dr. Wolfgang Diederichs

Ruhr-Universität Bochum

Urologische Klinik

Marienhospital

Widumerstrasse 8

W-4690 Herne

Federal Republic of Germany 